\title{
6.6 Разработка технологии плодоовощных напитков, обогащенных биологической добавкой коллагеном
}

\section{АННОТАЦИЯ}

Проблема старения человека очень актуальна сегодня. Механизмы старения тесно связаны со снижением в организме людей такого белкового вещества, как коллаген. Он составляет основу соединительной ткани человека, обеспечивает её прочность и эластичность. С возрастом запасы коллагена истощаются, его синтез замедляется, что ведет к появлению первых признаков старения. Одной из возможностей восполнения количества этого важного компонента является использование в питании коллагенсодержащих продуктов. Цель исследования - разработка рецептур нового ассортимента соковых продуктов на основе плодоовощного сырья, обогащенных коллагеном. Изучен ассортимент и показатели качества разных видов коллагена растительного и животного происхождения - томатного, говяжьего, свиного и рыбного. Определено оптимальное количество этой биологически активной добавки для обогащения соковых продуктов, при обеспечении требуемого качества напитков. Исследовано сохранение активных свойств различных видов коллагена в питьевом продукте, при его рецептурном содержании фракционный и аминокислотный состав белка. Полученные данные позволили выбрать предпочтительный вид и рецептурное количество коллагена для обогащения продуктов. Также изучены органолептические и физико-химические показатели качества разработанных коллагенсодержащих композиций и доказано их соответствие нормативно-техническим документам. Проведенные научно-исследовательские работы свидетельствуют о целесообразности разработанных рецептур новых плодоовощных соковых продуктов, обогащенных коллагеном. Новый ассортимент напитков обладает лечебнопрофилактическими свойствами, так как поставляет в организм человека важный биологически активный компонент, который тормозит негативные изменения, связанные с процессами старения. 
Ключевые слова: напитки плодоовощные, животный и растительный коллаген, белок, аминокислоты, рецептуры, показатели качества.

\section{ВВЕДЕНИЕ}

В процессе жизнедеятельности организма непрерывно расходуются питательные вещества, выполняющие пластическую и энергетическую функции. Источником питательных веществ являются различные продукты питания, состоящие из комплекса сложных белков, жиров и углеводов. Наличие или отсутствие сбалансированного по белку рациона не даёт нормально развиваться биологическому организму. Следовательно, белок - это одно из мощных средств воздействия на популяцию человека на планете, на формирование умственно и физически развитого индивидуума. Трудно переоценить роль белков соединительных тканей, которые не сбалансированы по аминокислотному составу, но выполняют важнейшие пластические функции. Так, например, в последнее время роль коллагеновых белков в питании пересмотрена и его причисляют к белкам молодости, красоты и здоровья. Однако для его достаточного биосинтеза необходим витамин С в требуемом количестве для преобразования пролина в оксипролин, либо пополнение оксипролина за счет перевариваемых форм коллагена. Гидролизованный коллаген - это самая лучшая форма для усвоения организмом. С помощью различных кислот и щелочей в промышленных условиях коллагеновые волокна расщепляются на самые мелкие составляющие (аминокислоты и пептиды), кроме того, удаляются лишние балластные вещества, не имеющие отношения к коллагену. Имеется положительный опыт применения ферментов в получении растворимых форм коллагена, который нашел применение в косметологии, медицине и пищевой промышленности. Растворимый коллагена служит доступным источником оксипролина, необходимого для биосинтеза собственного коллагена. Поэтому, разработка ассортимента пищевых продуктов в состав которых входит биологически активная добавка - коллаген, сегодня очень актуальна. 
В последнее время все чаще ученые рассматривают коллаген и его производные как активную пищевую добавку, которая входит в состав пищевого продукта либо принимается человеком перорально. Питьевой коллаген активно используется спортсменами, сторонниками активного образа жизни, а также в разнообразных диетах, он рекомендуется к приему только ограниченное время и в определенном рецептурном соотношении с другими компонентами. В тоже время, существуют такие продукты питания как сокосодержащие напитки, нектары, которые содержат в своем составе много полезных компонентов и добавление к ним коллагена повысит их пищевую ценность. При использовании коллагена в соках и напитках необходимо учитывать его количество и активную кислотность продукта, которая влияет на процесс его набухания, что, непременно, отразится на органолептических показателях напитков [341].

Коллаген и один из его производных - желатин оказывает благоприятное воздействие на кожный покров человека, улучшает состояние кожи, ее упругость и влажность. Большая часть коллагена, содержится в коллагеновых волокнах и является их главным структурным компонентом, основная функция которого, связана с формированием и поддержанием специфической структуры органов и тканей в процессе роста и развития организма. Стабилизирующая, опорная функция коллагенового волокна обеспечивается за счет его необычных биологических и физико-химических свойств (метаболическая инертность, устойчивость к действию различных веществ и т. д.) [341]. Биосинтез коллагена и образование коллагеновых волокон значительно усиливаются при различных процессах, сопровождающихся разрастанием соединительной ткани (склеротические изменения сосудов и органов, хронические воспалительные изменения, заживление ран и переломов костей и др.). Патологические изменения обмена и структуры коллагена у человека возникают при системных заболеваниях соединительной ткани (ревматизм, склеродермия и др.), при этом идут изменения биосинтеза или распада коллагеновых белков, что приводит к нарушению механических свойств коллагенового волокна и, следовательно, опорных свойств соединительной ткани. Коллаген и желатин применяют для 
изготовления сосудистых протезов и пленок для лечения ран, а также в связи с использованием в некоторых отраслях промышленности (пищевой, легкой) [342345].

Были проведены исследования, которые продемонстрировали положительный эффект перорального применение специфических биоактивных коллагеновых добавок на физиологию кожи. Если употреблять коллаген и в то же время достаточно двигаться, правильно питаться или даже полностью изменить свой образ жизни, действие коллагена будет ощутимо на любом жизненном этапе [346-351].

Коллаген в качестве добавки целесообразно вводить в те продукты, которые используются людьми постоянно, а не эпизодически. Были разработаны рецептуры функциональных фруктовых соковых напитков, обогащенных содержащих коллагеном из смесей апельсинового, яблочного и белого виноградного сока, содержащих такие ингредиенты, как гидролизованный рыбный коллаген, лимонная кислота, аскорбиновая кислота и натуральный мятный ароматизатор. Результаты показывают, что состав с добавлением 2,5\% гидролизованного коллагена был оптимальным. Добавление гидролизованного коллагена увеличивало содержание белка в напитках с 0,56 до 2,22-2,48 г/100 мл. Результаты биодоступности in-vitro показали, что апельсиновый $(95,37 \%)$ и яблочный (90,71\%) напитки показали более высокую биодоступность (5-14\%), чем смеси белого виноградного сока, для этого определяли содержание аскорбиновой кислоты, общее содержание фенолов, антиоксидантную способности в напитках [352].

Разработана технологии напитков типа «Шорли» с коллагеном на основе минеральных вод природного происхождения. В их состав входит различное плодовоягодное сырье. Проведено обоснование компонентного состава и рецептуры напитков на основе растворимого коллагена рыбного происхождения. Использовали гидрат коллагеновых белков из кожи толстолобика в виде 2\% дисперсии, три вида питьевой минеральной воды: «Славяновская», «Ессентуки 4» и «Нарзан». В качестве плодово-ягодного сырья были выбраны соки малины, 
вишни и черной смородины. Полученные образцы напитков обладают хорошими органолептическими и физико-химическими показателями [353].

Результаты проведенных исследований показывают, что основное внимание не было обращено на ежедневно потребляемые продукты, такие как различные соковые продукты.

Поэтому актуально провести исследования по разработке технологии продуктов питания с использованием коллагена, у которых регулируется значение величины активной кислотности для наиболее эффективного использования полезных свойств этого вещества, разработать рецептурные композиции соков и сокосодержащих напитков с использованием различных видов коллагена для создания легко усваиваемой пищевой продукции для решения проблем опорного двигательного аппарата и других функций организма человека. Сокосодержащие плодоовощные продукты являются источником витаминов, ферментов, органических кислот, которые способствуют гидролизу коллагена, получению его растворимой формы и источника оксипролина.

В работе разработаны рецептуры сокосодержащих плодоовощных напитков с использованием различных видов животного и растительного коллагена. Основной целью исследования являлось обеспечение минимизации влияния коллагена на органолептические и физико-химические характеристики разработанных рецептурных композиций готовой продукции при соблюдении его полезных биологических активных свойств.

\section{ОСНОВНАЯ ЧАСТЬ}

Определены органолептические показатели коллагенов: стабильность водного раствора, запах, вкус, как в высушенном состоянии, так и в растворенном, которые представлены в табл. 1: 
Таблица 1 - Органолептические показатели коллагена

\begin{tabular}{|l|l|l|l|}
\hline Вид коллагена & $\begin{array}{c}\text { Коллаген в } \\
\text { высушенном } \\
\text { состоянии }\end{array}$ & $\begin{array}{l}\text { Водный раствор } \\
\text { коллагена }\end{array}$ & $\begin{array}{c}\text { Стабильность } \\
\text { водного раствора }\end{array}$ \\
\hline Говяжий & Без запаха & $\begin{array}{l}\text { Без постороннего } \\
\text { запаха и вкуса }\end{array}$ & $\begin{array}{l}\text { Осадок } \\
\text { отсутствует, } \\
\text { незначительное } \\
\text { помутнение }\end{array}$ \\
\hline Свиной & Без запаха & $\begin{array}{l}\text { Без постороннего } \\
\text { запаха и вкуса }\end{array}$ & $\begin{array}{l}\text { Образование } \\
\text { взвесей и } \\
\text { небольших } \\
\text { хлопьев }\end{array}$ \\
\hline Рыбный & $\begin{array}{l}\text { Резкий рыбный } \\
\text { запах }\end{array}$ & $\begin{array}{l}\text { Резкий рыбный } \\
\text { запах и вкус }\end{array}$ & $\begin{array}{l}\text { Образование } \\
\text { хлопьев }\end{array}$ \\
\hline $\begin{array}{l}\text { Растительный } \\
\text { томатный) }\end{array}$ & $\begin{array}{l}\text { Запах томатного } \\
\text { сырья }\end{array}$ & $\begin{array}{l}\text { Запах и вкус } \\
\text { свойственные } \\
\text { томатам }\end{array}$ & $\begin{array}{l}\text { Образование } \\
\text { осадка }\end{array}$ \\
\hline
\end{tabular}

Как следует из табл. 1 по органолептическим характеристикам свиной, рыбный, томатный коллагены имеют либо резкие запах и вкус, либо дают образование взвесей, хлопьев и осадка при растворении, а коллаген растительного происхождения томатный обладает специфическим, характерным запахом томатов, поэтому его можно использовать только в соковых продуктах, в рецептуру которых входят томатопродукты. Поэтому, для исследований выбран коллаген животного происхождения, говяжий, в сухом виде.

Для окончательного выбора коллагеновой добавки, которую можно использовать в производстве соковой продукции, были проведены опыты по определению зависимости содержания белка от массовой доли коллагеновых добавок для всех исследованных образцов. Эксперименты проводили с использованием образца продукта "Нектар «Свекла-манго-яблоко», как наиболее чувствительного по органолептическим характеристикам - цвету, вкусу и запаху из изученных сокосодержащих продуктов. Входящий в него компонент - сок свекольный, окрашивает продукт в яркий бардовый тон. Добавление сухого коллагена, имеющего белый цвет, изменяет цвет напитка. Во вкусе базового продукта чувствуется яблочная нота, которая изменяется при 
внесении коллагеновой добавки. В запахе исходной рецептуры присутствует аромат манго, который изменяется даже с учетом того, что говяжий и свиной коллаген по органолептическим показателям не имеют запаха. Таким образом, выбранный для исследований продукт является самым подходящим. Массовую долю коллагена в рецептуре нектара варьировали от 5.0 до 20.0\% к общей массе продукта, который вводили за счет уменьшения в рецептуре основного сокового компонента. Такой интервал выбран с целью определения влияния не только вида коллагена на массовую долю белка в конечном продукте, но и для получения данных о содержании в конечном продукте массовой доли аминокислот - метионина, триптофана и оксипролина, которые характеризуют наличие коллагена в продукте (так как только коллаген положительно влияет на соединительные ткани организма) и отсутствие его денатурации в желатин. Результаты представлены в табл. 2:

Таблица 2 - Зависимость содержания белка от массовой доли коллагеновой добавки в продукте

\begin{tabular}{|l|c|c|c|c|c|}
\hline \multirow{2}{*}{ Вид коллагена } & \multicolumn{5}{|c|}{ Массовая доля коллагеновой добавки в соковом продукте, \% } \\
\cline { 1 - 6 } & 0 & 5 & 10 & 15 & 20 \\
\hline & \multicolumn{5}{|c|}{ Содержание белка, \% } \\
\hline Говяжий & 2,01 & 2,62 & 2,40 & 2,55 & 2,60 \\
\hline Свиной & 2,01 & 2,63 & 2,59 & 2,85 & 3,20 \\
\hline Рыбный & 2,01 & 2,62 & 2,58 & 2,88 & 3,15 \\
\hline Растительный & 2,01 & 2,21 & 2,33 & 2,40 & 2,62 \\
\hline
\end{tabular}

Анализируя опытные данные, можно отметить, что начиная с 10\% массовой доли коллагеновых добавок к рецептуре, начинается резкий рост белка в соковом продукте. При этом, в диапазоне от 5\% до 10\% для всех видов коллагена, содержание белка в соковом продукте остается практически постоянной величиной. Но увеличение коллагеновой добавки в рецептуре от 5\% до 20\% и выше приводит к ухудшению «питьевого» качества соковых продуктов, т.е. возникновению густой консистенции. Поэтому выбрана концентрация коллагеновой добавки в сокосодержащих продуктах на уровне 5\% от суммарной рецептуры продукта. 
Проведены исследования по определению фракционного состава белка в продукте с массовой долей 5\% коллагена к основной рецептуре, данные которых представлены в табл. 3:

Таблица 3 - Фракционный состав белков в продукте с массовой долей коллагена $5 \%$

\begin{tabular}{|c|c|c|c|c|}
\hline Вид коллагена & $\begin{array}{c}\text { Водная } \\
\text { фракция* } \\
\text { мг/дм }\end{array}$ & $\begin{array}{c}\text { Солевая } \\
\text { фракция*, } \\
\text { мг/дм }\end{array}$ & $\begin{array}{c}\text { Спиртовая } \\
\text { фракция*, } \\
\text { мг/дм }{ }^{3}\end{array}$ & $\begin{array}{c}\text { Щелочная } \\
\text { фракция*, } \\
\text { мг/дм }\end{array}$ \\
\hline Говяжий & 93.16 & 5.14 & 1.10 & 0.60 \\
\hline Свиной & 85.98 & 5.06 & 6.40 & 2.56 \\
\hline Рыбный & 97.15 & 1.50 & 1.30 & следы \\
\hline Растительный & 99.40 & следы & следы & следы \\
\hline
\end{tabular}

*на абсолютно сухое вещество после лиофильной сушки образцов продукта.

Экспериментальные данные показали, что растительный коллаген вносит в продукт только водную фракцию белка. Коллаген животного происхождения, говяжий и свиной, вносит все виды исследуемых фракций в максимальном количестве, поэтому эти виды коллагена можно использовать для обогащения соковых продуктов.

Проведены опыты по определению содержания основных аминокислот, характеризующих наличие в соковом продукте коллагена (метионина, триптофана и оксипролина). Результаты этих экспериментов приведены в табл. 4:

Таблица 4 - Массовая доля метионина, триптофана и оксипролина в продукте

\begin{tabular}{|l|c|c|c|c|c|c|}
\hline \multirow{2}{*}{$\begin{array}{c}\text { Вид } \\
\text { коллагена }\end{array}$} & \multicolumn{2}{|c|}{ Метионин, \% } & \multicolumn{2}{c|}{ Триптофан, \% } & \multicolumn{2}{c|}{ Оксипролин, \% } \\
\cline { 1 - 7 } & $*$ & $* *$ & $*$ & $* *$ & $*$ & $* *$ \\
\hline Говяжий & 0.009867 & 0.6676 & 0.00296 & 0.020 & 0.342009 & 2.314 \\
\hline Свиной & 0.10919 & 0.6176 & 0.000792 & 0.005 & 0.421314 & 2.383 \\
\hline Рыбный & 0.018089 & 0.1142 & 0.00583 & 0.035 & 0.382577 & 2.295 \\
\hline Растительный & 0.16649 & 1.153 & 0.002383 & 0.0165 & 0.028302 & 0.196 \\
\hline Без коллагена & 0.001808 & 0.1142 & 0.000792 & 0.005 & 0.007492 & 0.0473 \\
\hline
\end{tabular}

*на исходный продукт, **на абсолютно сухое вещество 
Анализируя полученные данные в табл. 4, видим, что количество аминокислот в соковом продукте практически равно количеству этих же аминокислот в продукте, который изготовлен по исходной рецептуре без добавления коллагена. Только количество оксипролина существенно отличается от количества других аминокислот. Так же добавленный в рецептуру нектара коллаген гидролизуется в продукте в один из его маркеров оксипролин, что показывает катаболизм этого белка. При внесении в продукт рыбного и свиного коллагена не изменяется количество метионина и триптофана, по сравнению с исходной рецептурой, соответственно. Эксперимент показал, что в образце нектара только говяжий коллаген обеспечил увеличение всех исследуемых аминокислот и, в связи с этим, как добавку выбираем коллаген животного происхождения - говяжий. Наиболее предпочтительным, является коллаген животного происхождения - говяжий в качестве биологической добавки в плодоовощные нектары и напитки, в количестве 5\%, что обеспечит максимальное обогащение готового продукта коллагеном.

Проведены исследования по определению ассортимента соковой продукции, при этом учитывалось, что коллаген является белком и его введение в жидкие продукты приводит к возникновению в объеме продуктов желеобразной субстанции, которая проводит к ухудшению внешнего вида готовой продукции, консистенции; к появлению посторонних органолептических ощущений (запаха, вкуса) готовой продукции. Этот ассортимент включает в себя нектары и напитки, которые за счет наличия в составе достаточно большого количества плодовой мякоти (6-12\%) [354] естественным образом скрывают от потребителя наличие желеобразной субстанции в объеме продукта, а равномерное распределение мякоти по всему продуктовому объему, обеспеченное процессом гомогенизации продукта при его изготовлении, не позволяет проявляться непривычным органолептическим ощущениям при потреблении готовой продукции. 
При разработке рецептур сокосодержащих купажированных продуктов, обогащенных коллагеном, за основу приняты базовые рецептуры нектаров и напитков с мякотью в соответствии с нормативной документацией [355-359].

Рецептуры сокосодержащих продуктов, обогащенных коллагеном, \% на 1 тонну готового продукта:

- Нектар «Персик»: пюре персиковое - 7, пюре яблочное - 18, бета-каротин 10\% DSM - 0,05, глюкозо-фруктозный сироп 0,2 - 0,13, кислота лимонная - 0,1, кислота аскорбиновая - 0,05, говяжий коллаген -5 ; вода подготовленная (обратноосмотическая обработка) - 69,67.

- Нектар «Банан - клубника»: сахарный сироп - 8,9; концентрат яблочного сока $-6,5$; концентрат клубничного сока $-6,0$; концентрат сока черной смородины $-6,0$; пюре банановое $-8,7$;кислота лимонная - 0,11; пектин яблочный $-0,1 ;$ говяжий коллаген -5 ; вода подготовленная (обратноосмотическая обработка) - 48,69.

- Нектар «Яблоко - Гуава - Банан»: пюре яблочное - 10; пюре гуавы белой - 12 ; пюре банановое - 8,5; глюкозо-фруктозный сироп - 11,2; кислота лимонная $-0,085$; кислота аскорбиновая $-0,085$; пектин яблочный $-0,1$; говяжий коллаген - 5; вода подготовленная (обратноосмотическая обработка) 53,03 .

- Нектар «Яблоко - Груша»: пюре яблочное - 80; пюре грушевое - 40; глюкозо-фруктозный сироп $42-12,2$; кислота лимонная - 0,07; кислота аскорбиновая - 0,07; говяжий коллаген - 5; вода подготовленная (обратноосмотическая обработка) - 53,04.

Напиток «Черника - Ежевика - Малина»: сок черники концентрированный - 5; глюкозо-фруктозный сироп - 12,2; кислота лимонная - 0,07; кислота аскорбиновая - 0,07; натуральный ароматизатор «Черника» 0,$01 ;$ натуральный ароматизатор «Ежевика-Малина» - 0,01 ; говяжий коллаген 5; вода подготовленная (обратноосмотическая обработка) - 76,64. 
- Нектар «Свекла - Манго - Яблоко»: сок яблочный концентрированный 5,6; сок свекольный концентрированный - 15,5; пюре манго концентрированное - 10; сахарный сироп - 8,9; кислота лимонная $-0,07$; говяжий коллаген -5 ; вода подготовленная (обратноосмотическая обработка) - 54,93.

- Напиток «Яблоко - Мята»: сок яблочный концентрированный - 6,5; глюкозо-фруктозный сироп - 12,2; кислота лимонная - 0,07; кислота аскорбиновая - 0,07; натуральный ароматизатор «Яблоко» - 0,01; натуральный ароматизатор «Мята» - 0,01; говяжий коллаген - 5; вода подготовленная (обратноосмотическая обработка) - 76,14.

Проведены органолептические исследования, полученных образцов нектаров и напитков с мякотью, обогащенных коллагеном. Органолептические показатели разработанных рецептур соковых продуктов с коллагеном позволили определить оптимальные рецептуры - это соки и напитки с мякотью в ассортименте с добавлением говяжьего коллагена в количестве $5 \%$. Результаты исследований позволяют сделать однозначный вывод о том, что полученные сокосодержащие продукты (нектары, напитки), в состав которых добавлен коллаген в количестве 5\%, полностью удовлетворяют потребительским требованиям к этой пищевой продукции, в том числе и по консистенции.

Также были исследованы и определены физико-химические показатели разработанных базовых образцов нектаров и напитков с мякотью, обогащенных коллагеном, опыты проводились в 5-ти кратной повторности, критерий Стьюдента (t) 0,05) и представлены в табл. 5: 
Таблица 5 - Физико-химические показатели сокосодержащих продуктов, обогащенных коллагеном

\begin{tabular}{|c|c|c|c|c|c|c|}
\hline \multirow[b]{2}{*}{$\begin{array}{c}\text { Наименова } \\
\text { ние } \\
\text { сокового } \\
\text { продукта }\end{array}$} & \multicolumn{6}{|c|}{ Наименование физико-химических показателей } \\
\hline & $\begin{array}{c}\text { Массовая } \\
\text { доля } \\
\text { раствори } \\
\text { мых } \\
\text { сухих } \\
\text { веществ, } \\
\text { \% }\end{array}$ & $\begin{array}{c}\text { Активная } \\
\text { кислотно } \\
\text { сть, рН }\end{array}$ & $\begin{array}{c}\text { Массо- } \\
\text { вая доля } \\
\text { титруе- } \\
\text { мых } \\
\text { кислот, } \\
\text { \% }\end{array}$ & $\begin{array}{c}\text { Массо- } \\
\text { вая } \\
\text { доля } \\
\text { мякоти } \\
\text {, \% }\end{array}$ & $\begin{array}{c}\text { Показате } \\
\text { ль цвета, } \\
\text { Abs 420 } \\
\text { нм, } \\
10 \text { мм }\end{array}$ & $\begin{array}{c}\text { Показатель } \\
\text { Brix, \% }\end{array}$ \\
\hline 1 & 2 & 3 & 4 & 5 & 6 & 7 \\
\hline $\begin{array}{c}\text { Нектар } \\
\text { «Персик» }\end{array}$ & 11,0 & 3,6 & 0,3 & 9,2 & 4,340 & $12,7 \pm 0,1$ \\
\hline $\begin{array}{c}\text { Нектар } \\
\text { «Банан - } \\
\text { Клубника» }\end{array}$ & 11,0 & 3,8 & 0,25 & 15,0 & 3,553 & $12,3 \pm 0,1$ \\
\hline $\begin{array}{c}\text { Нектар } \\
\text { «Яблоко - } \\
\text { Гуава - } \\
\text { Банан» }\end{array}$ & 10,0 & 3,8 & 0,28 & 14,0 & 4,060 & $12,0 \pm 0,1$ \\
\hline $\begin{array}{c}\text { Нектар } \\
\text { «Яблоко - } \\
\text { Груша» }\end{array}$ & 10,0 & 3,8 & 0,25 & 15,0 & 3,358 & $12,0 \pm 0,1$ \\
\hline $\begin{array}{c}\text { Напиток } \\
\text { «Черника - } \\
\text { Ежевика - } \\
\text { Малина» }\end{array}$ & 8,0 & 2,8 & 0,24 & 2,5 & 4,256 & $9,0 \pm 0,1$ \\
\hline $\begin{array}{c}\text { Нектар } \\
\text { «Свекла - } \\
\text { Манго - } \\
\text { Яблоко» }\end{array}$ & 12,0 & 3,5 & 0,25 & 2,7 & 3,339 & $13,0 \pm 0,1$ \\
\hline $\begin{array}{c}\text { Напиток } \\
\text { «Яблоко- } \\
\text { Мята» }\end{array}$ & 9,0 & 3,5 & 0,22 & 1,2 & 2,893 & $9,1 \pm 0,1$ \\
\hline $\begin{array}{c}\text { Показатели в } \\
\text { соответствии } \\
\text { с } \\
\text { нормативным } \\
\text { документом }\end{array}$ & $\begin{array}{c}\text { Не менее } \\
\text { 9,0 для } \\
\text { нектаров } \\
\text { Не менее } \\
\text { 8,0 для } \\
\text { напитков }\end{array}$ & $\begin{array}{c}\text { Не менее } \\
\text { 3,5 для } \\
\text { нектаров } \\
\text { Не менее } \\
\text { 2,5 для } \\
\text { напитков }\end{array}$ & $\begin{array}{c}\text { Не менее } \\
0,25 \text { для } \\
\text { нектаров } \\
\text { Не менее } \\
\text { 0,22 для } \\
\text { напитков }\end{array}$ & $\begin{array}{c}\text { Не } \\
\text { менее } \\
9,0 \text { для } \\
\text { нектаров } \\
\text { Не } \\
\text { менее } \\
1,0 \text { для } \\
\text { напитко } \\
\text { в }\end{array}$ & $\begin{array}{c}\text { Не менее } \\
\text { 3,0 для } \\
\text { нектаров } \\
\text { Не менее } \\
\text { 2,0 для } \\
\text { напитков }\end{array}$ & $\begin{array}{l}\text { Не менее } 11,0 \\
\text { для нектаров } \\
\text { Не менее 9,0 } \\
\text { для напитков }\end{array}$ \\
\hline
\end{tabular}


Как следует, из представленных в таблице результатов исследования физико-химических показателей разработанного ассортимента нектаров и напитков с мякотью с коллагеном, их значения полностью соответствуют действующей нормативно-технический документации на данный вид пищевой продукции.

\section{ВЫВОДЫ}

Исследованы ассортимент и органолептические показатели разных видов коллагена животного и растительного происхождения.

Изучены особенности различных видов коллагена для возможности их использования в сокосодержащих продуктах. Определена массовая доля коллагена в готовых сокосодержащих продуктах, которая составляет 5\% и позволяет получить напиток по качеству в соответствии с нормативным документом.

Исследована степень сохранения биологически активной белковой добавки в готовых соковых продуктах (фракционный и аминокислотный состав), что позволило определить предпочтительный вид коллагена. Определено, что наиболее приемлемым видом коллагена для обогащения сокосодержащих продуктов является коллаген животного происхождения - говяжий.

Разработаны рецептуры сокосодержащих продуктов с коллагеном - это плодоовощные и ягодные, купажированные нектары и напитки с мякотью, замутненные.

Исследованы органолептические и физико-химические показатели качества готовых соковых напитков, обогащенных коллагеном и их соответствие требованиям нормативно-технической документации. 